\title{
Comparative Study Of Manual Mathematics Science Common Core (1976) "Royaume Du Maroc" And Manuals Of The New Reform Course In Linear Algebra Of Vector Space And Affine Space.
}

\author{
Radouane Kasour ${ }^{1}$, Naceur Achtaich ${ }^{2}$ Brahim Nachit $^{3}$,Abdelwahed Namir ${ }^{4}$ and \\ Mohammed Talbi ${ }^{5}$, \\ 1, 3, 5 Observatory for Research in Pedagogy and Didactics University (ORPDU), University Hassan -II- \\ Mohammedia, Casablanca, Morocco. \\ ${ }^{1,2}$ Laboratory analysis, Modeling and Simulation ( LAMS), University Hassan -II-Mohammedia, Casablanca, \\ Morocco. \\ ${ }^{3,4}$ Laboratory of Information Technology and Modeling (LTIM), University Hassan -II- Mohammedia, \\ Casablanca, Morocco
}

\begin{abstract}
In our article we present a comparison of the linear algebra course: vector space and affine space that exist in Moroccan manual level mathematics science common core (1976) "ROYAUME DU MAROC" and manuals of the new reform. In order to understand the origin of the problems and difficulties faced by students of the first year university physics and chemistry option.
\end{abstract}

Keywords: Linear algebra, formal system, formalism, semantic, syntax

\section{Introduction}

Linear algebra is an important part of teaching the first-year at scientist universities in most countries. However, difficulties in teaching and learning were found everywhere. Faced with this situation, for more than twenty years of research programs on teaching linear algebra have developed in several places. Thus, today there is a comparison between the linear algebra lessons given to the generation of the eighties and the other of the new reform, starting with the observation of professors from the University Hassan II Ben M 'sik who say that the ropy level of today's students in linear algebra. This comparison will be done on the high school textbooks of the two generations in linear algebra.

\section{Problem}

University professors in the Faculty of Science Ben M'sik found that the students have difficulties in "Linear Algebra", while this matter was easy for students from years 80s and 90s.

And this is clear by examining the results of the two generations.

So the questions arise:

What is the cause of lowering the level of the students?

What is this problem? And how can it be remedied?

\section{Hypothesis}

Maybe the adopted pedagogy by each generation is the cause of this reduction.

Maybe the nature of matter in general "mathematical" form a formal system based on axioms is not consistent with the followed pedagogy and especially "the theory of situations."

\section{Theoretical Framework}

A-Language

A of a sign relating to its language is a set of signs with a semantic, and usually of a syntax More commonly, the language is a means of communication.

\section{Semantic property}

Called semantic properties possible transfer to an individual property.

Syntactic property property.

Called syntactic properties of a sign relating to its possible return to a relationship between signs 


\section{Formal system}

A formal system consists on one hand of conventions that allow you to write formulas (list of characters used and how to arrange them) and on the other hand of transformation rules or rules of inference, which can transform a in another formula.

\section{Formal symbolic system}

1 - includes rules

According GGG 2003 is composed by three characters

2 - all its signifiers can be reduced by decomposing a finite lexicon of basic meaning.

3 - The rules should be reduced to simple conditions concatenation of lexical elements, requirements, compliance determines the "well-formed expressions" system

\section{B- Formalism:}

According to Klages, formalism is "the thought by pure signs." This definition, in the early twentieth century, anticipates the best illustration of the formal language, computer programming, whose recurring terms, protocols, controls, routines, sequences, do not admit any approximation.

Formalism is a formal system consists of a formal language and semantics represented by a computational or deductive system. Formalism aims to represent unambiguously a subject of study in science. Formalisms are very common in mathematics, mathematical logic and theoretical Computer Science,

\section{C- Situation :}

\section{Definition: the situation (Brousseau)}

This situation is all the circumstances in which a person is, and relationships that unite the community.

The learning situations are situations that are used to teach

- Environment student (implemented and manipulated by the teacher) $=$ tool

- Environment whole of the student, the teacher and the educational system

\section{Definition: adidactic situations (Brousseau)}

"The teacher refuses to act as owner of the knowledge he wants to be seen. The student knows that the problem has been selected to acquire new knowledge, but he must also know that this knowledge is fully justified by the internal logic of the situation." P. 59

\section{Framework Practice}

\begin{tabular}{|c|c|}
\hline $\begin{array}{l}\text { Manual level mathematics fifth grade } \\
\text { science (1976) Kingdom Of Morocco }\end{array}$ & $\begin{array}{l}\text { Manual (fi al rihab riyadiyate) } \\
\text { science core and technology core }\end{array}$ \\
\hline $\begin{array}{l}\text { Vector space: page } 236 \text { to } 274 \\
\text { Well detailed on } 39 \text { pages. } \\
\text { I-External Act } \\
\text { Notion of vector space over IR } \\
\text { II-Combination II-linear subspaces. } \\
\text { III-bases of a vector space over IR. }\end{array}$ & $\begin{array}{l}\text { Vector space: } \\
\text { Does not exist in the secondary school } \\
\text { textbooks }\end{array}$ \\
\hline $\begin{array}{l}\text { Affine space: page } 275 \text { to } 308 \\
\text { Well detailed on } 34 \text { pages } \\
\text { The lesson began with an introduction that } \\
\text { presents the objective of the course for } \\
\text { which the student will learn. } \\
\text { I-affine structure. }\end{array}$ & $\begin{array}{l}\text { The straight line in the plan: } \\
\text { The lesson began with activities as exercises of } \\
\text { the third secondary year. }\end{array}$ \\
\hline
\end{tabular}

The first note is the absence of the vector space lesson and also affine in the manuals of the new reform, so we will not have algebraic or axiomatic approach, while these knowledge have the appearance of formalism. 


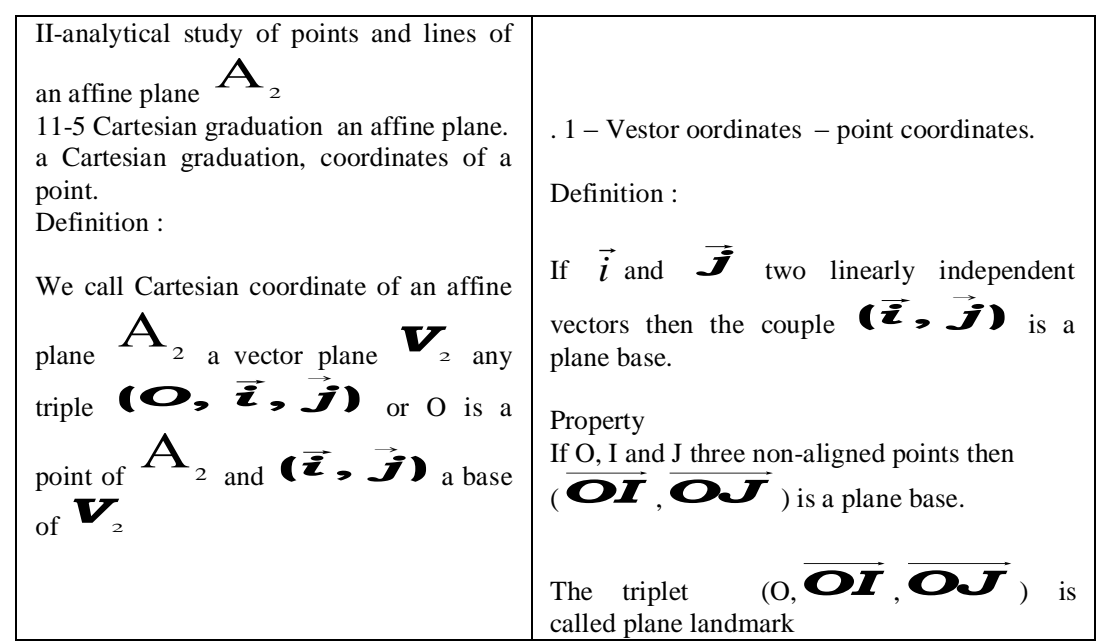

We note that the definition of Cartesian is built in the manual of the science common core (1976) and the course is a good example of the formal system, or where we can clearly see that the rules are returning to "well-formed expressions" system

Whereas the manual (fi rihab arriyadiyate) (2008) core science and technology does not have the formal aspect allowed to write formulas and other transformation rules or rules of inference, for transforming a formula into another.

So we can conclude that manual science common core (1976) presents the formalism aspect, however, that the manual (fi rihab arriyadiyate) (2008) common science core and technology does not present it.

\section{Conclusion}

We find that the absence of the vector space lesson in school textbooks of the new reform, while the lesson was in the program in the years eighty's, is a major factor among others are responsible for lowering level students at the first academic year physics and chemistry in linear algebra, and to overcome this problem we must respect the notion of formalism and formal system in the construction of mathematics lessons in high school.

\section{REFERENCES}

[1] Gilles-Gaston Granger, " Philosophie, Langage, Science“" les Ulis Cedex A, France, EDP Sciences. 2003

[2] Desanti, Jean-Toussaint, La Philosophie silencieuse ou Critique des philosophies de la science, Paris, Éditions du Seuil,. 1975

[3] Ludwig, Les principes de la caractérologie, Paris, Delachaux et Niestlé, 1950

[4] Jean-Luis Dessailles, Aux origines du langage : une histoire naturelle de la parole, Paris, HEMES Science Publicatio2000

[5] http://agora.qc.ca/mot.nsf/Dossiers/Formalisme

[6] http://fr.wikipedia.org/wiki/Grammaire_formelle\#Langages

[7] http://fr.wikipedia.org/wiki/Connaissance

[8] http://fr.wikipedia.org/wiki/Gestion_des_connaissances\#Connaissances_tacites_vs_connaissances_explicites http://www.universalis.fr/encyclopedie/formalisme/1-1-idee-de-connaissance-formelle/ Authors Article: Etienne Balibar (masterassistant at the University of Paris-I), Pierre MACHEREY (maitre-assistant at the University of Paris-I)

[10] Jean-Luc dorier Mathematics ditactic team, Educational research about teaching linear algebra Leibniz Laboratory, Grenoble Publication date: May 24, 2006

في رحاب الرياضيات الجذوع المشتركة للتعليم الثانوي التأهلي , جذع العلوم و جذع التكنولوجيا عبد العزيز منتاج 2008 (11)

[12] Royaume du MAROC manuel mathématiques 5e sciences Librairie des Ecoles - casablanca 1976 